Published in: Karanika-Murray, M., Pontes, H.M., Griffiths, M.D. \& Biron, C. (2015). Sickness presenteeism determines job satisfaction via affective-motivational states. Social Science and Medicine, 139, 100-106.

Sickness presenteeism determines job satisfaction via affective-motivational states

\author{
Maria Karanika-Murray, Halley M. Pontes, Mark D. Griffiths, \\ Nottingham Trent University, United Kingdom \\ \& Caroline Biron \\ Laval University, Canada
}

Corresponding author details:

Dr Maria Karanika-Murray, Nottingham Trent University, Division of Psychology, Burton Street, Nottingham NG1 4BU, United Kingdom. Tel: 0115 8482425. Email: maria.karanikamurray@ntu.ac.uk

Acknowledgements:

This project was funded by Nottingham Trent University (SPUR project 2012) awarder to Maria Karanika-Murray \& Mark Griffiths 


\title{
Sickness presenteeism determines job satisfaction via affective-motivational states
}

\begin{abstract}
Research on the consequences of sickness presenteeism, or the phenomenon of attending work whilst ill, has focused predominantly on identifying its economic, health, and absenteeism outcomes, neglecting important attitudinal-motivational outcomes. A mediation model of sickness presenteeism as a determinant of job satisfaction via affective-motivational states (specifically engagement with work and addiction to work) is proposed. This model adds to the current literature, by focusing on (i) job satisfaction as an outcome of presenteeism, and (ii) the psychological processes associated with this. It posits presenteeism as psychological absence and work engagement and work addiction as motivational states that originate in that. An online survey was completed by 158 office workers on sickness presenteeism, work engagement, work addiction, and job satisfaction. The results of bootstrapped mediation analysis with observable variables supported the model. Sickness presenteeism was negatively associated with job satisfaction. This relationship was fully mediated by both engagement with work and addiction to work, explaining a total of $48.07 \%$ of the variance in job satisfaction. Despite the small sample, the data provide preliminary support for the model. Given that there is currently no available research on the attitudinal consequences of presenteeism, these findings offer promise for advancing theorising in this area.
\end{abstract}

Keywords: presenteeism, job satisfaction, work engagement, work addiction, psychological presence 


\section{Sickness presenteeism determines job satisfaction via affective-motivational states}

Sickness presenteeism is the phenomenon of attending work whilst ill (Aronsson \& Gustafsson 2005). Presenteeism can be deleterious to employee health and costly to organizations. It is a risk factor for future poor health, mental well-being (Gustafsson \& Marklund, 2011), and sickness absence (Bergström et al., 2009; Bergstrom, Bodin, Hagberg, Aronsson, \& Josephson, 2009; Demerouti, Le Blanc, Bakker, Schaufeli, \& Hox, 2009), even in the long-term (Kivimaki et al., 2005; Taloyan et al., 2012). Understanding the outcomes of presenteeism is therefore paramount.

There are two issues in the field that need to be addressed. First, the vast majority of research on presenteeism has focused predominantly on its prevalence, determinants, and financial costs, and has omitted research into potential motivational and attitudinal consequences (Karanika-Murray, Ikhlaq, Williams, \& Biron, under review). Second, the field is conceptually poor and in need of development (Dickson, 2013; Johns, 2011). The present study aims to address these important omissions. It achieves this by presenting a model of presenteeism and three attitudinal-motivational outcomes.

Insofar as presenteeism may signify physical presence and psychological absence, it can be linked with affective-motivational states (i.e., work engagement, work addiction, and job satisfaction). Affective-motivational states are rooted in physical and psychological presence. Presenteeism may deplete satisfaction with work because, mentally and physically, the individual is unable to perform to their full capacity and achieve expected outcomes. When psychological presence is jeopardised, as in the case of temporary illness, people may disengage from work but still feel a need to work by being physically present in the workplace. Therefore, weakened psychological presence may be linked to weakened affective evaluations of work (i.e., job satisfaction) through its effect on affective-motivational states (i.e., work engagement and work addiction). In the next section, recent conceptual and 
empirical work on presenteeism is briefly outlined, highlighting gaps and areas of dissent, and presenting a model and a study that could help to bridge these gaps.

\section{The phenomenon of sickness presenteeism}

Sickness presenteeism describes the phenomenon of people working despite ill-health that would normally require rest and absence, and not performing to their full capacity (Aronsson \& Gustafsson, 2005; Cooper, 1996; Vingård, Alexanderson \& Norlund, 2004). It also represents a drive to be physically present and has been linked to future sickness absence, impaired recovery, and reduced on-the-job effectiveness (Bergstrom et al., 2009; Caverley, Cunningham, \& MacGregor, 2007; Hansson, Boström, \& Harms-Ringdahl, 2006; Kivimaki et al., 2005; Schultz \& Edington, 2007). Persistent presenteeism can lead to long-term health consequences (Bergström et al., 2009; Bergstrom et al., 2009; Demerouti et al., 2009) including raised incidence of coronary heart disease (Kivimaki et al., 2005). Others define presenteeism as productivity loss due to the presence of physical, mental and/or emotional problems (Dickson, 2013; Schultz \& Edington, 2007, p. 548). The present study focuses on sickness presenteeism and deliberately excludes its effect on performance.

Three notable models have been proposed to explain the processes that lead to presenteeism. Johansson and Lundberg's (2004) illness flexibility model suggests that attendance requirements (i.e., negative consequences employees face due to absence) and adjustment latitude (i.e., modifying workloads) can determine sickness attendance and absence. Similarly, Aronsson and Gustafsson (2005) described two types of attendance demands that influence presenteeism: personal factors (e.g., financial situation, individual boundarylessness) and work factors (e.g., control over pace of work, replaceability). Finally, Johns's (2010) model proposed that a health event interrupts productivity and triggers a choice between presenteeism and absenteeism and that presenteeism decisions are influenced 
by factors in the work context (i.e., ease of replacement, absence policy) and individual factors (i.e., personality and work attitudes).

At present, little conceptual work has attempted to understand its consequences on affective and motivational outcomes (Karanika-Murray et al., under review). By examining the links between presenteeism and affective-motivational outcomes, a number of overarching weakness in this relatively new field are addressed, elucidating the nature of presenteeism, building upon and refining earlier research, and opening new avenues for theorising.

\section{Presenteeism as voluntary behaviour: physical presence and psychological absence}

Presenteeism can also be a volitional behaviour. For example, Johns's (2010) model posits that a choice between presenteeism and absenteeism is triggered when a health event interrupts productivity, and that this choice is based on work-related and individual factors. Aronsson and Gustafsson (2005) suggested that presenteeism and absenteeism are alternatives of the same decision process, whereas Løkke Nielsen (2008) also distinguished between a voluntary and involuntary part in absenteeism, a behaviour closely related to presenteeism (Karanika-Murray et al., under review). When one's ailment is severe, the choice to be absent or present does not present itself. However, in the case of minor and non-serious health ailments, the individual has a choice to work to the extent that their health status permits that. Under mild perceived ill-health and personal choice, presenteeism denotes one's extent of physical presence and psychological absence in work. The effort to remain psychologically present despite illness may impact on affective evaluation of work (i.e., job satisfaction) and affective-motivational aspects of work (i.e., work engagement and work addiction). In the next section, how this may happen is discussed. 


\section{Presenteeism and job satisfaction}

Being present at work under impaired health contributes to work outputs that are most probably poorer quality than would be achieved at optimal health (Gifford \& Jinnett, 2014). This implies physical presence coupled with psychological absence, and may contribute to job (dis)satisfaction. To the extent that presenteeism can be viewed as a choice made under pressure and under reduced capacity to work, it may therefore also result in reduced job satisfaction.

Deviating from the majority of current research, the present study approaches job satisfaction as an outcome rather than a determinant of presenteeism. Research on job satisfaction as a determinant of presenteeism is inconclusive. On one hand, correlational studies have detected weak negative associations between presenteeism and job satisfaction $[r$ $=-.14, p<.05$ (Caverley et al., 2007) and between $r=-.10$ in Belgium and $r=-.22$ in the UK, $p<.05$ (Claes, 2011). Conversely, Cocker, Martin, Scott, Venn and Sanderson (2013) found no relationships between job satisfaction and number of days of presenteeism in the past month. On the other hand, job satisfaction is conceptualised as a positive presence and motivational factor that contributes to increased presenteeism rates (Aronsson \& Gustafsson, 2005). As far as the authors are aware, only one study, a qualitative investigation, has shown job satisfaction to be an important motivator to stay at work despite the pain (i.e., for people with chronic nonspecific musculoskeletal pain) (de Vries, Brouwer, Groothoff, Geertzen, \& Reneman, 2011). In contrast to the majority of the current (and contradictory) research, the present study's conceptual viewpoint is that job satisfaction is an evaluative outcome of presenteeism behaviour. Empirically, however, the following hypothesis is limited by the nature of the data (see Method section).

Hypothesis 1: Presenteeism is negatively associated with job satisfaction. 


\section{The motivational qualities of presenteeism}

No study has explained the relationship between presenteeism, affective evaluative reactions to work, and job satisfaction. It is proposed that because presenteeism restricts psychological presence, this mechanism relates to its relationship with motivational states. Although a range of intrinsic and extrinsic motives can determine the occurrence of presenteeism (Biron \& Saksvik, 2009), it is possible that presenteeism may also lead to affective-motivational states. A link between presenteeism and motivation is intuitive but not clear in the literature. However, viewing presenteeism as psychological presence (Kahn, 1992), or absence, allows us to understand the motivational qualities of presenteeism. When ill-health interrupts psychological presence and leads to presenteeism behaviour, the individual may experience deleterious consequences as well as changes in affect and motivation. The present study examines one positive (i.e., work engagement) and one negative (i.e., work addiction) affective-motivational state.

\section{Relationships of presenteeism to work engagement and work addiction}

Engagement is a positive affective-motivational state. However, feeling a need to be physically present coupled with being psychologically absent may be associated with becoming disengaged from work,. Indeed, presenteeism has been strongly linked with poorer engagement at work (Admasachew \& Dawson, 2011; Baker-McClearn, Greasley, Dale, \& Griffith, 2010). Because presenteeism can represent a moral obligation to work even when ill, it may also be associated with addiction to work (Griffiths, 2011), a negative affectivemotivational state. Empirical evidence supports this link. Johns (2010) suggested that workaholics and people with a strong work ethic are more likely to display presenteeism. Presentees may work because they feel a compulsion to work and are likely to work excessively even when feeling unwell (Griffiths \& Karanika-Murray, 2012). However, the reverse is also plausible. As an attempt to sustain psychological presence and reach normal 
levels of performance, presenteeism may fuel tendencies to work excessively and compulsively. In turn, because of reduced work outputs, this may be linked to dissatisfaction.

It should also be noted that the concept of work addiction as used in this study deviates from that of workaholism (Schaufeli, Taris, \& Bakker, 2006; Schaufeli, Bakker, \& Salanova, 2006), as it describes addiction to work as a genuine addiction (Andreassen et al., 2014; Griffiths, 2011; Griffiths \& Karanika-Murray, 2012). Because workaholism is described as an unhealthy and unproductive compulsion to work (Schaufeli et al., 2006) rather than as a real addiction, it is arguably different from addiction to work. In this study, the concept of work addiction is used. From the aforementioned literature the following hypothesis emerges:

\section{Hypothesis 2: Work engagement and work addiction fully mediate the relationship} between sickness presenteeism and job satisfaction. Specifically, (a) sickness presenteeism is negatively related to work engagement that is, in turn, positively related to job satisfaction, and (b) sickness presenteeism is positively related to work addiction, which is, in turn, negatively related to job satisfaction.

\section{Method}

\section{Participants and Procedure}

An online survey on the determinants of positive and negative work behaviours was distributed to employees in three UK organizations (a design consultancy, a printing company, and a local government office) to allow a good spread of occupations and settings. All were invited to participate by their line managers during work time or at their own time. Email invitations containing a web link to the survey were followed by two reminders. A total of 194 returned questionnaires (c. $65 \%$ response rate) of which 158 were useable ( $n=83$ [47\%] men and $\mathrm{n}=93$ [53\%] women; age $M_{\text {age }}=39$ years, $S D=11.42$, range: $18-67$ years; tenure $M=8.8$ years, range: $<1-35$ years $)$. One-third of participants $(\mathrm{n}=59)$ were 
responsible for managing others. Over one-third (39\%) were professionals (e.g., engineer, accountant, systems analyst), 35.6\% provided clerical and administrative support (e.g., secretary, billing clerk, office supervisor), and $15.3 \%$ were executive or senior managers. The remaining $10.1 \%$ described their main role as technical support, sales, service occupation, operator or labourer. The right to withdraw at any time, confidentiality of the data, and anonymity of responses were explained to participants at the start of the survey. To our knowledge, in the participant organizations there were no 'sanctions' for employees who reported sick, suggesting that pressure to attend work while sick was not associated with situational determinants such as financial pressures.

\section{Measures}

Sickness presenteeism was assessed using the item "As far as you can recall, has it happened over the previous 12 months that you have gone to work despite feeling that you really should have taken sick leave due to your state of health?" (Aronsson, Gustafsson, \& Dallner, 2000). Response options were 'no, never', 'yes, once', ‘yes, 2-5 times', and 'yes, more than 5 times'. The measure reflects the frequency of presenteeism behaviour as work attendance in spite of illness and does not conflate attendance behaviour with reduced performance. This single item has been used widely as a reliable short measure of sickness presenteeism (Biron, Brun, \& Ivers, 2006; Demerouti et al., 2009; Vézina et al., 2011).

Work engagement was measured using the short version of the Utrecht Work Engagement Scale (UWES-9, Schaufeli et al., 2006). Participants were asked to indicate whether they had ever felt a particular way about their work (e.g., "At my job, I feel strong and vigorous", "I am enthusiastic about my job", and "I am immersed in my work”) on a 7point Likert scale (from $0=$ never to $6=$ always). The measure has been shown to have high internal consistency ( $\alpha=.85$ to .92 , Schaufeli et al., 2006), with the present study yielding $\alpha=$ 
.94 for the overall work engagement scale and $\alpha=.87, .90$, and .74 for vigour, dedication, and absorption, respectively.

Work addiction was measured with the 7-item Bergen Work Addiction Scale (Andreassen et al., 2012). Respondents were asked to rate a number of questions on their work within a 12-month window (e.g., "Thought of how you could free up more time to work?", "Been told by others to cut down on work without listening to them?", "Deprioritized hobbies, leisure activities, and exercise because of your work?") on a 5-point frequency scale (from $1=$ never, to $5=$ always). The measure has good psychometric properties (Andreassen et al., 2012). Cronbach's alpha for the present study was .86.

Job satisfaction was assessed with a composite measure of three items adapted from the Job Diagnostic Survey (Hackman \& Oldham, 1980) (e.g., "In general, my job measures up to the sort of job I wanted when I took it"). Respondents were asked to indicate how true the three statements were for them, on a 7 -point scale (from $1=$ strongly disagree to $7=$ strongly agree). Cronbach's alpha for the present study was .88.

Because managerial responsibility (i.e., responsibility for supervising others) and tenure can be conceptually linked to work engagement, they were included in the study as potential control variables. Tenure was assessed in number of years whereas managerial responsibility on a binary scale. However, neither these nor any of the demographic variables were associated with job satisfaction or the mediators and were therefore not included in subsequent analyses.

\section{Statistical Analysis}

The statistical analyses comprised of (i) descriptive statistics of the main sample's characteristics, (ii) correlational analysis of the main variables in the study alongside their descriptive statistics, (iii) reliability analysis to assess the internal consistency of the measures 
utilised, (iv) bootstrapped correlation with bias-corrected accelerated $95 \%$ confidence interval based on 10,000 samples of the main variables in order to provide more robust results, and (v) mediation analysis with observable variables using Preacher and Hayes's (2004) framework to investigate the total, direct, and indirect effects on the basis of 10,000 bootstrapped samples and bias-corrected and accelerated confidence intervals with $95 \%$ level of confidence.

Additionally, all the analyses were carried out on IBM SPSS Statistics for Windows, Version 20 and PROCESS version 2.11 (Hayes, 2012). Prior to the analyses, all variables used in the models were checked for multicollinearity (by examining the Variation Inflation Factors) and no issues were detected since all VIF values were $<5$ and not beyond the threshold of 10 (Yan \& Su, 2009). In terms of missing values, no variable had more than 5\% of missing values and all analyses were carried using pairwise exclusion of cases presenting missing values in any of the variables that were modelled.

\section{Results}

Table 1 presents the correlation means (M), standard deviations (SD), and zero-order Pearson correlations (r), and reliability coefficients (Cronbach's alpha) for the study variables. Consistent with Hypothesis 1, sickness presenteeism was negatively correlated with job satisfaction $(\mathrm{r}=-.32, p \leq .01)$. In addition, sickness presenteeism was correlated negatively with work engagement $(\mathrm{r}=-.21, p \leq .001)$ and positively with work addiction $(\mathrm{r}=.37, p \leq$ .001). The bivariate relationships between the study variables are therefore confirmed, further justifying the mediation analysis.

[Insert Table 1 about here]

In order to examine the mediation hypothesis (Hypothesis 2), one analysis was performed using the bootstrapping method as discussed in Preacher and Hayes (2004). This approach allows the computation of bootstrapped samples and bias-corrected and accelerated 
confidence intervals to test indirect mediation. Preacher and Kelley's (2011) Kappa-squared was also computed to ascertain the effect sizes of any indirect effects observed in the simple mediation model. Preacher and Hayes's (2004) approach is preferred over Baron and Kenny's (1986) approach because of the latter's limitation concerning its sensitivity to normality deviations, usually requiring larger samples sizes. Moreover, the former has increased power in comparison to older methodologies and is preferred over the Sobel test and even over SEM approaches to mediation for small sample sizes.

One of the main advantages of bootstrapped mediation (Preacher \& Hayes, 2004) is that unlike the normal theory approach (Baron \& Kenny, 1986; Sobel, 1982), no assumption is made about the shape of the sampling distribution. Bootstrap confidence intervals better respect the irregularity of the sampling distribution of absorption and, as a result, yield inferences that are more likely to be accurate than when the normal theory approach is used. When used to test a hypothesis, the result is a test with higher power (Hayes, 2013).

Table 2 and Figure 1 present the results of the mediation analysis for Hypothesis 2. Results from the simple regression suggested that presenteeism significantly predicted work engagement (i.e., Path $\left.\mathrm{a}_{1}\right)(b=-2.74, \mathrm{SE}=1.02, t=-2.69, p=.008)$ and work addiction (i.e., Path $\left.\mathrm{a}_{2}\right)(b=-2.77, \mathrm{SE}=0.56, t=4.91, p<.0001)$. Moreover, the $\mathrm{r}$-squared values obtained suggested that presenteeism explained $4.42 \%\left(\mathrm{R}^{2}=.0442\right)$ of the variance in work engagement and $13.39 \%\left(\mathrm{R}^{2}=.1339\right)$ of the variance in work addiction.

Additionally, results of the regression of job satisfaction predicted from work engagement (i.e., Path $b_{1}$ ), work addiction (i.e., Path $b_{2}$ ), and presenteeism (i.e., Path c') suggested that job satisfaction was significantly predicted by work engagement $(b=0.25, \mathrm{SE}$ $=0.02, t=10.47, p<.0001)$, work addiction $(b=-0.13, \mathrm{SE}=0.04, t=-2.85, p=.005)$ but not presenteeism $(b=-0.64, \mathrm{SE}=0.32, t=-3.12, p=.06)$. Moreover, this latter model including all variables in the model explained around $48.0 \%\left(\mathrm{R}^{2}=.4807\right)$ of the total 
variance in job satisfaction. In relation to the total effect, direct effect, and indirect effect, the results obtained were based on 10,000 bootstrapped samples and bias-corrected and accelerated confidence intervals with $95 \%$ level of confidence.

Furthermore, the results indicated that the total effect of presenteeism on job satisfaction was statistically significant $(b=-1.68 ; \mathrm{SE}=0.40 ; t=-4.18 ; p<.0001)$. Conversely, the direct effect $(b=-0.64 ; \mathrm{SE}=0.34 ; t=-1.88, p=.062)$ did not reach statistical significance. Furthermore, the results given by the total indirect effect - and the absence of a statistical significance in the relationship between presenteeism and job satisfaction after controlling for the two mediators (i.e., Path $c^{\prime}$ ) - suggested that work engagement and work addiction fully mediated (Little, Card, Bovaird, Preacher, \& Crandall, 2007) the relationship between presenteeism and job satisfaction $(b=-1.04, \mathrm{SE}=0.30, \mathrm{BCa} \mathrm{CI} 95 \%[-1.643,-$ 0.484]) and because this confidence interval does not contain and is entirely below zero, there is clear evidence that the total indirect effect is statistically significant (Hayes, 2013).

Bootstrap confidence intervals for pairwise comparisons between specific indirect effects were also analysed. These comparisons are based on the notion that confidence intervals that do not contain zero provide evidence that the two indirect effects are statistically different from each other, whereas a confidence interval that straddles zero supports the claim of no difference between the specific indirect effects (Hayes, 2013).

Accordingly, the point estimate of the difference between the specific indirect effects for work engagement and work addiction $(b=-0.35)$ has an associated BCa CI95\% [-1.015, 0.271, Boot $\mathrm{SE}=0.33$ ] which suggests that these two indirect effects are statistically different from each other. In other words, the indirect effect of presenteeism on job satisfaction through work engagement is statistically different from the indirect effect through work addiction. 
Lastly, further analyses of the strength of the indirect effects associated with each mediator variable independently (i.e., controlling for the remaining mediators) suggested that work engagement $(b=-0.69)$ is the strongest mediator of the relationship between presenteeism and job satisfaction compared to the role of work addiction $(b=-0.35)$ in this relationship. It is worth noting that the comparisons of the strength of the indirect effects are simply informative and cannot be tested for differences with p-values by any statistical test.

\section{[Insert Table 2 and Figure 1 about here]}

\section{Discussion}

The findings reported in the present study offer preliminary support for the hypothesis that (i) presenteeism is negatively associated with job satisfaction, and (ii) work engagement and addiction to work fully mediate the relationship between presenteeism and job satisfaction. As such, the data support the proposed theoretical model which views work engagement and work addiction as the psychological mechanisms that mediate between presenteeism and job satisfaction. Therefore, there is evidence that presenteeism behaviour may decrease individuals' evaluations of their work through its impact on two affectivemotivational states: work engagement and work addiction. Being occupied with work while ill may reinforce individuals' propensity to addiction to work and reduce their engagement with work. The data also indicated that although presentees may be occupied with work in a sub-optimal manner and be disengaged from work, the engagement may be rewarding enough to maintain their satisfaction with work.

As this is the first empirical study to examine the relationships between presenteeism and work-related affective-motivational states, it advances three major contributions. First, it focuses on the psychological consequences instead of on the determinants or financial costs of presenteeism. The vast majority of research in this field has been concentrated on evaluating 
the impact of various health risks and health conditions on the financial costs it represents for organizations in terms of productivity losses (Schultz, 2007). Studies that define presenteeism as a volitional behaviour have mainly focused on its determinants, whether they relate to individual, work or organizational pressures which constrain one's decision to work or not when ill (Hansen \& Andersen, 2008; Nyberg, Westerlund, Hanson, \& Theorell, 2008; Collins, \& Cartwright, 2012; Robertson, Leach, Doerner, \& Smeed, 2012). The present study supports the relevance of considering the psychological processes that result from one's decision to attend work despite illness.

Second, it helps to strengthen theoretical understanding related to the psychological outcomes of presenteeism. The majority have been conducted on an ad-hoc basis without clear theoretical frameworks (Karanika-Murray et al., under review). Sickness presenteeism is neither a lone aspect of productivity nor an end outcome of health status (authors' reference). Rather, it is one link among complex associations with important consequences for affect and motivation. Therefore, it is important to not only focus on the costs and determinants of presenteeism but also towards an understanding of the effects of presenteeism behaviour on affective and motivational impairments. An advancement on the present study would be to address the temporal ordering of presenteeism, work addiction, work engagement, and job satisfaction.

Third, it indicates that work engagement and work addiction together, as positive and negative affective-motivational states respectively, may be relevant for understanding work outcomes related to presenteeism. Viewing presenteeism as increased physical presence and reduced psychological presence helped to achieve this. Currently, there is little research into engagement and addiction to work as combined forces that drive evaluations of work. It may be argued that work engagement may act as a protective factor whereas work addiction may 
act as an exposure mechanism for the effects of presenteeism. Together, these constructs explained almost half of all the variance in job satisfaction scores.

Although this study focused on presenteeism under non-serious health problems, future research should examine how presenteeism impacts on work engagement, work addiction, and job satisfaction under varying ill-health conditions and disease severity and in the short and longer term. It would be beneficial to examine the proposed model under different types of health conditions, for example, mild or severe, and temporary or chronic. The present findings may not apply to presentees with chronic illness, for whom permanent presenteeism may be associated with different affective-motivational outcomes. Such finegrained analysis would help to understand the health and contextual conditions under which presenteeism is associated with a range of affective-motivational outcomes.

Although the present study has both theoretical and psychometric strengths, it comes with a number of limitations and one caution that may restrict the interpretation and application of its findings. First, there are limits to the generalizability of the findings. Although the sample size was adequate for the analytical techniques and although the sample was obtained from a range of organizations, these findings may only be accepted as preliminary until the findings have been replicated with a larger sample. Second, the fact that the data were self-report means that memory recall biases and social desirability biases may have impacted on the accuracy of the responses. Third, the exclusive use of self-report suggests the possibility of common method variance, and therefore the validity of the model should be further examined with a longitudinal approach and objective measures. Fourth, the sample was self-selected, which is a risk for any research into extreme work behaviours such as sickness presenteeism and work addiction. Finally, the study used a cross-sectional design, and although the relationships were carefully theorised, only a longitudinal approach can further examine reciprocal and more dynamic relationships between sickness presenteeism 
and its determinants and consequences. Nevertheless, these limitations do not invalidate the principles supported by the data collected in the present study.

Finding ways to manage presenteeism is paramount, as presenteeism has also been viewed as a public health hazard (Widera, Chang, \& Chen, 2010). It is strongly associated with future ill-health among not only presentees, but also their colleagues (Irvine, 2011; Jena, Baldwin, Daugherty, Meltzer, \& Arora, 2010; Widera et al., 2010) and with the spread of infectious disease (Widera et al., 2010). This makes sense, as overwork may lower immune function and may make people more susceptible to opportunistic infections and accidents (B. T. Johnson, personal correspondence). Therefore, it may be possible, from these preliminary findings, to draw implications for intervention practice.

However, implications for intervention research can only be tentative as it is important to collect more empirical evidence. Here, the potential implications of more theoretically grounded and focused research on presenteeism are outlined. Improved models of presenteeism can help to develop efficient interventions. Although evidence from studies of common health problems point to an overall beneficial effect of work on health (Waddell \& Burton, 2006) and although presenteeism can encourage a positive adjustment and return to work when the health impairment is not severe (Ashby \& Mahdon, 2010), in practice this depends on how well presenteeism is managed. To achieve this, all relevant parameters ought to be considered, including the severity and contagiousness of the illness, its recovery prognosis, the individual's fitness to work, and the resources in the workplace to facilitate functional presenteeism. It is also worthwhile for future research to examine the links between presenteeism and affective-motivational states in the long-term, perhaps as an indication of such adjustment and/or the success of interventions. What is certain is that a more comprehensive understanding of presenteeism will enable informed interventions and perhaps address the unfortunate observations that controlled intervention studies aimed at reducing 
presenteeism have found weak links with future health status (Christensen, Overgaard, Hansen, Søgaard, \& Holtermann, 2013), that there is a lack of association between the availability of health and wellness programs and the prevalence of presenteeism (Bustillos \& Trigoso, 2013) which is worrying (Capps \& Harkey, 2008; Coffeng et al., 2014). Advanced research on presenteeism can help to address the limited advice currently available concerning its management and moreover to capitalise on functional presenteeism.

Research in the field of presenteeism has largely been descriptive and atheoretical. By offering a model that explains the affective and motivational outcomes of presenteeism, the present study offers a baseline that could further bolster conceptual understanding of the consequences of presenteeism, lead to novel and testable hypotheses, and point toward new research directions in sickness presenteeism. 


\section{References}

Admasachew, L., \& Dawson, J. (2011). The association between presenteeism and engagement of national health service staff. Journal of Health Services Research \& Policy, 16 Suppl 1, 29-33. doi:10.1258/jhsrp.2010.010085

Andreassen, C. S., Griffiths, M. D., Hetland, J., \& Pallesen, S. (2012). Development of a work addiction scale. Scandinavian Journal of Psychology, 53(3), 265-272.

Andreassen, C. S., Griffiths, M. D., Hetland, J., Kravina, L., Jensen, F., \& Pallesen, S. (2014). The prevalence of workaholism: A survey study in a nationally representative sample of norwegian employees. PloS One, 9(8), e102446.

Aronsson, G., \& Gustafsson, K. (2005). Sickness presenteeism: Prevalence, attendancepressure factors, and an outline of a model for research. Journal of Occupational and Environmental Medicine, 47(9), 958-966.

Aronsson, G., Gustafsson, K., \& Dallner, M. (2000). Sick but yet at work. an empirical study of sickness presenteeism. Journal of Epidemiology and Community Health, 54(7), 502509.

Ashby, K., \& Mahdon, M. (2010). Why do employees come to work when ill?: An investigation into sickness presence in the workplace Work Foundation.

Baker-McClearn, D., Greasley, K., Dale, J., \& Griffith, F. (2010). Absence management and presenteeism: The pressures on employees to attend work and the impact of attendance on performance. Human Resource Management Journal, 20(3), 311-328.

Baron, R. M., \& Kenny, D. A. (1986). The moderator-mediator variable distinction in social psychological research: Conceptual, strategic, and statistical considerations. Journal of Personality and Social Psychology, 51(6), 1173. 
Bergström, G., Bodin, L., Hagberg, J., Lindh, T., Aronsson, G., \& Josephson, M. (2009). Does sickness presenteeism have an impact on future general health? International Archives of Occupational and Environmental Health, 82(10), 1179-1190.

Bergstrom, G., Bodin, L., Hagberg, J., Aronsson, G., \& Josephson, M. (2009). Sickness presenteeism today, sickness absenteeism tomorrow? A prospective study on sickness presenteeism and future sickness absenteeism. Journal of Occupational and Environmental Medicine / American College of Occupational and Environmental Medicine, 51(6), 629-638. doi:10.1097/JOM.0b013e3181a8281b

Bierla, I., Huver, B., \& Richard, S. (2013). New evidence on absenteeism and presenteeism. The International Journal of Human Resource Management, 24(7), 1536-1550.

Biron, C., Brun, J. -., \& Ivers, H. (2006). At work but ill: Psychosocial work environment and wellbeing determinants of presenteeism propensity. Journal of Public Mental Health, $5(4), 26-37$.

Biron, C., \& Saksvik, P. Ø. (2009). Sickness presenteeism and attendance pressure factors: Implications for practice. International Handbook of Work and Health Psychology, 3

Burton, W. N., Conti, D. J., Chen, C., Schultz, A. B., \& Edington, D. W. (2002). The economic burden of lost productivity due to migraine headache: A specific worksite analysis. Journal of Occupational and Environmental Medicine, 44(6), 523-529.

Bustillos, A. S., \& Trigoso, O. O. (2013). Access to health programs at the workplace and the reduction of work presenteeism: A population-based cross-sectional study. Journal of Occupational and Environmental Medicine / American College of Occupational and Environmental Medicine, 55(11), 1318-1322. doi:10.1097/JOM.0b013e3182a299e8

Capps, K., \& Harkey, J. B. (2008). Employee health and productivity management programs: The use of incentives. ().National Association of Manufacturers. 
Caverley, N., Cunningham, J. B., \& MacGregor, J. N. (2007). Sickness presenteeism, sickness absenteeism, and health following restructuring in a public service organization. Journal of Management Studies, 44(2), 304-319.

Christensen, J. R., Overgaard, K., Hansen, K., Søgaard, K., \& Holtermann, A. (2013). Effects on presenteeism and absenteeism from a 1-year workplace randomized controlled trial among health care workers. Journal of Occupational and Environmental Medicine I American College of Occupational and Environmental Medicine, 55(10), 1186-1190. doi:10.1097/JOM.0b013e31829b2816

Claes, R. (2011). Employee correlates of sickness presence: A study across four european countries. Work \& Stress, 25(3), 224-242.

Cocker, F., Martin, A., Scott, J., Venn, A., \& Sanderson, K. (2013). Psychological distress, related work attendance, and productivity loss in small-to-medium enterprise owner/managers. International Journal of Environmental Research and Public Health, 10(10), 5062-5082.

Coffeng, J. K., Hendriksen, I. J., Duijts, S. F., Twisk, J. W., van Mechelen, W., \& Boot, C. R. (2014). Effectiveness of a combined social and physical environmental intervention on presenteeism, absenteeism, work performance, and work engagement in office employees. Journal of Occupational and Environmental Medicine, 56(3), 258-265.

Collins, A., \& Cartwright, S. (2012). Why come into work ill? Individual and organizational factors underlying presenteeism. Employee Relations, 34(4), 429-442. doi: doi:10.1108/01425451211236850

Cooper, C. L. (1996, Hot under the collar. Times Higher Education Supplement, 21 June de Vries, H. J., Brouwer, S., Groothoff, J. W., Geertzen, J. H., \& Reneman, M. F. (2011). Staying at work with chronic nonspecific musculoskeletal pain: A qualitative study of 
workers' experiences. BMC Musculoskeletal Disorders, 12, 126-2474-12-126. doi:10.1186/1471-2474-12-126

Demerouti, E., Le Blanc, P. M., Bakker, A. B., Schaufeli, W. B., \& Hox, J. (2009). Present but sick: A three-wave study on job demands, presenteeism and burnout. Career Development International, 14(1), 50-68.

Dickson, V. V. (2013). Presenteeism among older workers ( $\geq 45$ years) with coronary heart disease: An integrative literature review. Open Public Health Journal, 6, 31-41.

Gifford, B., \& Jinnett, K. (2014). Employees' work responses to episodes of illness: Evidence from the american time use survey. Journal of Occupational and Environmental Medicine, 56(2), 224-229.

Gilbreath, B. (2012). Educating managers to create healthy workplaces. Journal of Management Education, 36(2), 166-190.

Griffiths, M. D. (2011). Workaholism: A $21^{\text {st }}$ century addiction. The Psychologist: Bulletin of the British Psychological Society, 24, 740-744.

Griffiths, M. D., \& Karanika-Murray, M. (2012). Contextualising over-engagement in work: Towards a more global understanding of workaholism as an addiction. Journal of Behavioral Addictions, 1(3), 87-95. doi:10.1556/JBA.1.2012.002

Gustafsson, K., \& Marklund, S. (2011). Consequences of sickness presence and sickness absence on health and work ability: A swedish prospective cohort study. International Journal of Occupational Medicine and Environmental Health, 24(2), 153-165.

Hackman, J. R., \& Oldham, G. R. (1980). Work redesign. Reading, MA: Addison-Wesley.

Hansen, C. D., \& Andersen, J. H. (2008). Going ill to work-What personal circumstances, attitudes and work-related factors are associated with sickness presenteeism? Social Science \& Medicine, 67(6), 956-964. 
Hansson, M., Boström, C., \& Harms-Ringdahl, K. (2006). Sickness absence and sickness attendance—what people with neck or back pain think. Social Science \& Medicine, 62(9), 2183-2195.

Hayes, A. F. (2012). PROCESS: A versatile computational tool for observed variable mediation, moderation, and conditional process modeling [white paper]. ().

Hayes, A. F. (2013). Introduction to mediation, moderation, and conditional process analysis: Methodology in the social sciences (Kindle edition ed.) Guildford Press.

Irvine, A. (2011). Fit for work? the influence of sick pay and job flexibility on sickness absence and implications for presenteeism. Social Policy \& Administration, 45(7), 752769.

Jena, A. B., Baldwin, D. C., Daugherty, S. R., Meltzer, D. O., \& Arora, V. M. (2010). Presenteeism among resident physicians. JAMA, 304(11), 1166-1168.

Johansson, G., \& Lundberg, I. (2004). Adjustment latitude and attendance requirements as determinants of sickness absence or attendance. empirical tests of the illness flexibility model. Social Science \& Medicine, 58(10), 1857-1868.

Johns, G. (2010). Presenteeism in the workplace: A review and research agenda. Journal of Organizational Behavior, 31(4), 519-542.

Johns, G. (2011). Attendance dynamics at work: The antecedents and correlates of presenteeism, absenteeism, and productivity loss. Journal of Occupational Health Psychology, 16(4), 483.

Kahn, W. A. (1992). To be fully there: Psychological presence at work. Human Relations, 45(4), 321-349.

Karanika-Murray, M., Ikhlaq, S., Williams, J., \& Biron, C. (under review). Moving research and practice on presenteeism forward: A critical review. 
Kivimaki, M., Head, J., Ferrie, J. E., Hemingway, H., Shipley, M. J., Vahtera, J., \& Marmot, M. G. (2005). Working while ill as a risk factor for serious coronary events: The whitehall II study. American Journal of Public Health, 95(1), 98-102. doi:95/1/98 [pii]

Levin-Epstein, J. (2005). Presenteeism and Paid Sick Days,

Little, T. D., Card, N. A., Bovaird, J. A., Preacher, K. J., \& Crandall, C. S. (2007). Structural equation modeling of mediation and moderation with contextual factors. Modeling Contextual Effects in Longitudinal Studies, 1

Løkke Nielsen, A. (2008). Determinants of absenteeism in public organizations: A unit-level analysis of work absence in a large danish municipality. The International Journal of Human Resource Management, 19(7), 1330-1348.

Nyberg, A., Westerlund, H., Hanson, L. L. M., \& Theorell, T. (2008). Managerial leadership is associated with self-reported sickness absence and sickness presenteeism among Swedish men and women,. Scandinavian Journal of Public Health, 36(8), 803.

Preacher, K. J., \& Hayes, A. F. (2004). SPSS and SAS procedures for estimating indirect effects in simple mediation models. Behavior Research Methods, Instruments, \& Computers, 36(4), 717-731.

Preacher, K. J., \& Kelley, K. (2011). Effect size measures for mediation models: Quantitative strategies for communicating indirect effects. Psychological Methods, 16(2), 93.

Robertson, I. P., Leach, D. P., Doerner, N. P., \& Smeed, M. M. (2012). Poor Health but Not Absent: Prevalence, Predictors, and Outcomes of Presenteeism. Journal of Occupational \& Environmental Medicine, 54(11), 1344-1349.

Schaufeli, W. B., Bakker, A. B., \& Salanova, M. (2006). The measurement of work engagement with a short questionnaire a cross-national study. Educational and Psychological Measurement, 66(4), 701-716. 
Schaufeli, W. B., Taris, T. W., \& Bakker, A. B. (2006). Dr. jekyll or mr. hyde: On the differences between work engagement and workaholism. Research Companion to Working Time and Work Addiction, , 193-217.

Schultz, A. B. (2007). Employee health and presenteeism: A systematic review. Journal of Occupational Rehabilitation, 17(3), 547.

Schultz, A. B., \& Edington, D. W. (2007). Employee health and presenteeism: A systematic review. Journal of Occupational Rehabilitation, 17(3), 547-579.

Sobel, M. E. (1982). Asymptotic confidence intervals for indirect effects in structural equation models. In S. Leinhardt (Ed.), Sociological methodology (pp. 290-312). Washington, DC: American Sociological Association.

Stewart, W. F., Ricci, J. A., Chee, E., Hahn, S. R., \& Morganstein, D. (2003). Cost of lost productive work time among US workers with depression. Jama, 289(23), 3135-3144.

Taloyan, M., Aronsson, G., Leineweber, C., Hanson, L. M., Alexanderson, K., \& Westerlund, H. (2012). Sickness presenteeism predicts suboptimal self-rated health and sickness absence: A nationally representative study of the swedish working population. PLoS One, 7(9), e44721.

Vézina, M., Cloutier, E., Stock, S., Lippel, K., Fortin, É, Delisle, A., . . Prud'homme, P. (2011). Enquête québécoise sur des conditions de travail, d'emploi et de SST (EQCOTESST). ( No. R-691). Montréal: IRSST.

VingÅrd, E., Alexanderson, K., \& Norlund, A. (2004). . Sickness presence. Scandinavian Journal of Public Health, 32 (63 suppl), 216-221.

Waddell, G., \& Burton, A. K. (2006). Is work good for your health and well-being? The Stationery Office. 
Weaver, R. (2010). Cost of presenteeism surpasses absenteeism. Recuperado De

Http://Www.Examiner.Com/Human-Capital-in-Detroit/Cost-of-Presenteeism-SurpassesAbsenteeism [Links],

Widera, E., Chang, A., \& Chen, H. L. (2010). Presenteeism: A public health hazard. Journal of General Internal Medicine, 25(11), 1244-1247.

Yan, X., \& Su, X., Gang. (2009). Linear regression analysis: Theory and computing. London: World Scientific Publishing. 
Figure 1. The overall mediation model with standardized beta path coefficients and their explained variance $\left(\mathrm{R}^{2}\right)$ for the outcomes $(\mathrm{N}=158)$. Note: Mediation performed using $\mathrm{BCa}$ bootstrapped $95 \%$ confidence intervals based on 10,000 samples; Simple arrows: significant path coefficients, dotted arrows: non-significant path coefficients. ${ }^{*} \mathrm{p} \leq 0.05 ; * * \mathrm{p} \leq 0.01$. 
Table 1. Means, Standard Deviations, Reliability Coefficients and Correlations for the Study Variables

$\begin{array}{llllll}\text { M } & \text { SD } & \text { Cronbach's } \alpha & 1 & 2 & 3\end{array}$

1. Sickness presenteeism

2. Work engagement

$\begin{array}{llll}47.46 & 11.06 \quad .21 * * *\end{array}$

3. Job satisfaction

$15.30 \quad 4.62$

.88

$-.32 * * *$

$.65^{* * *}$

4. Work addiction

$24.62 \quad 5.73$

.86

$.37 * * *$

$.02-.21 * *$

Note: $* \mathrm{p} \leq .05, * * \mathrm{p} \leq .01, * * * \mathrm{p} \leq .001$, one-tailed. 
Table 2. Bootstrapped correlation matrix with Bias corrected accelerated 95\% confidence interval between Sickness Presenteeism, Work Engagement, Work Addiction, and Job Satisfaction

\begin{tabular}{lcccc}
\hline \multicolumn{1}{c}{ Measure } & $\begin{array}{c}\text { Sickness } \\
\text { Presenteeism }\end{array}$ & p-value & BCa95\% CI & $\mathrm{R}^{2}(\%)$ \\
\hline Work Engagement & $-.210^{* * *}$ & .008 & $-0.360,-0.054$ & 21.1 \\
Work Addiction & $.366^{* * *}$ & $<.0001$ & $0.223,0.492$ & 36.6 \\
Job Satisfaction & $-.317^{* * *}$ & $<.0001$ & $-0.463,-0.162$ & 31.7 \\
& & & \\
\hline Note: $\mathrm{N}=158 ;$ Bootstrap results are based on 10,000 bootstrap samples. $* \mathrm{p} \leq .05, * * \mathrm{p} \leq .01, * * * \mathrm{p} \leq .001$
\end{tabular}

